\title{
Endoscopic management of foreign bodies from the upper gastrointestinal tract in the hills of Himachal Pradesh, India: A 5-year tertiary care experience
}

\author{
Brij Sharma, Sujeet Raina ${ }^{1}$, Neetu Sharma², Rajesh Sharma, Neelam Grover ${ }^{3}$, Ashwani Sood ${ }^{3}$, \\ Surinder S. Sodhi ${ }^{4}$
}

Departments of Gastroenterology, ${ }^{2}$ Physiology, ${ }^{3}$ Pediatrics and ${ }^{4}$ Anesthesia, Indira Gandhi Medical College, Shimla, ${ }^{1}$ Department of Medicine, Dr. Rajendra Prasad Government Medical College, Kangra, Tanda, Himachal Pradesh, India

Abstract $\begin{aligned} & \text { Background and Aim: Foreign body (FB) ingestion is a common clinical problem in medical } \\ & \text { practice. Endoscopy is the therapeutic method of choice for the management of FBs with } \\ & \text { minimal complications. The aim of this study is to report our experience and outcome in a } \\ & \text { 5-year period in dealing with FBs in the upper gastrointestinal tract (GIT) using upper endoscopy. } \\ & \text { Materials and Methods: The records of all the patients who presented to the Department } \\ & \text { of Gastroenterology and who underwent endoscopic management between January, 2010, } \\ & \text { and December, 2014, were reviewed with details on age, sex, type of FBs and its anatomical } \\ & \text { location, treatments, and outcomes. Results: A total of } 59 \text { patients were analyzed. Their age } \\ & \text { ranged from } 2 \text { years to } 87 \text { years. A male predominance was noticed (59.4\%). Coins and chicken } \\ & \text { bone shared the most commonly encountered FBs. Esophagus was the most common site } \\ & \text { of trapping (49/59). Upper endoscopy successfully resolved the problem by FB removal in all } \\ & \text { patients, thus the overall success rate was } 100 \% \text {. No complications or mortalities due to FB } \\ & \text { ingestion or removal were observed throughout the study. Conclusion: In our experience, } \\ & \text { endoscopic management of FBs in upper GIT is a safe and highly effective procedure. }\end{aligned}$
Key words
Endoscopy, foreign body, Himalayan state

\section{Introduction}

Foreign body (FB) ingestion is a common medical emergency in both children and adults. Children constitute predominant population and constitute $80 \%$ of the total ingestions. Most FB ingestions in children are true FBs (nonfood objects) such

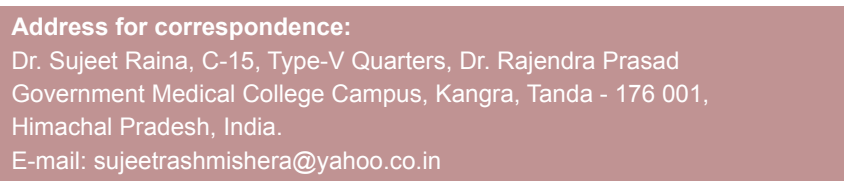

\begin{tabular}{|l|c|}
\hline \multicolumn{2}{|c|}{ Access this article online } \\
\hline \multirow{2}{*}{$\begin{array}{l}\text { Website: } \\
\text { www.jdeonline.in }\end{array}$} & Quick Response Code \\
\hline DOI: & 10.4103/0976-5042.195763 \\
& \\
\hline
\end{tabular}

as coins, marbles, buttons, safety pins, toys, magnets, and batteries. For the remaining $20 \%$ of ingestions that occur in adults, most are related to eating, leading to either bone or meat bolus impaction. ${ }^{[1]}$ On the other hand, intentional or accidental true FB ingestion in adults occurs more commonly in individuals with psychiatric disorders, developmental delay, alcohol intoxication or drug abusers, and those seeking secondary gain. ${ }^{[2]}$ Edentulous adults are also at a greater risk of ingesting FBs, including an obstructing food bolus or their dental prosthesis. ${ }^{[3]}$ The majority $(80 \%-90 \%)$ of the ingested

This is an open access article distributed under the terms of the Creative Commons Attribution-NonCommercial-ShareAlike 3.0 License, which allows others to remix, tweak, and build upon the work non-commercially, as long as the author is credited and the new creations are licensed under the identical terms.

For reprints contact: reprints@medknow.com

How to cite this article: Sharma B, Raina S, Sharma N, Sharma R, Grover N, Sood A, et al. Endoscopic management of foreign bodies from the upper gastrointestinal tract in the hills of Himachal Pradesh, India: A 5-year tertiary care experience. J Dig Endosc 2016;7:144-7. 
FBs negotiate esophagus and pass into stomach. They then traverse the entire gastrointestinal tract (GIT) and are expelled uneventfully spontaneously. Approximately, $10 \%-20 \%$ of the objects lodge in esophagus and require endoscopic procedure, whereas $1 \%$ or less require surgical procedures. ${ }^{[4-8]}$ Fortunately, mortality as a result of FBs' ingestion is extremely rare. The symptoms, signs, and complications produced depend on the nature, size, location, and duration of the FB ingestion in the GIT. ${ }^{[9]}$ FBs' ingestion and food bolus impaction are also a common problem in Himachal Pradesh, but an endoscopic setup is not always readily available in many hospitals of the state. A PubMed medical literature search with keywords "endoscopic management of foreign bodies in Himachal Pradesh, India," did not yield a single result. The aim of the current study was to report our clinical experiences in the endoscopic management of patients reporting a tertiary care center in the Himalayan state of North India.

\section{Materials and Methods}

In this hospital record-based retrospective descriptive study, we evaluated FB ingestion cases admitted to the hospital in the Department of Gastroenterology from January 2010 to December 2014. Data were collected from the department of the tertiary care hospital which caters to the hilly population of the physiogeographic zone of northwestern Himalayas of the state of Himachal Pradesh, India. Recorded information was entered in a precoded pro forma which included details on demography, clinical profile, treatment, and outcome. We evaluated the records of all FB ingestion cases where complete information was available as per the precoded pro forma parameters. The data collected were cross checked by two independent observers. The data were analyzed using SPSS computer software, version 15 (SPSS Inc., Chicago, IL, USA) and expressed as a number and a percentage for qualitative variables and as mean \pm standard deviation for quantitative variables. The study was approved by college Ethics Committee.

\section{Results}

A total of 59 patients were admitted with FB ingestion over a period of 5 years. The patients were in the age range of 2 years to 87 years. The mean age was $36.4 \pm 25.5$ years. Males constituted $59.4 \%$ of the patients. The age group distribution is shown in Table 1. The mean duration of presentation was $36.4 \pm 25.5 \mathrm{~h}$. Twenty-two patients presented within $24 \mathrm{~h}$ and were managed. Thirty-seven patients presented beyond 2 days. Five patients presented 12 days later which included one patient who presented after 35 days of denture ingestion. The majority of FBs found were coins and chicken bone; each making up $28.8 \%$ [Table 2]. The coins belonged to the denomination of 50 paisa to 10 rupees. The diameters of these coins varied from $22 \mathrm{~mm}$ to $27 \mathrm{~mm}$. Dentures were the second most frequent $(20.3 \%)$ and meat pieces were third (6.8\%). Other FBs included orange pieces, fish bone, coconut piece, mango, hair pin, nail, needle, and safety pin. [Figures 1 and 2a, b] The esophagus was the most common lodgment site of ingested FBs, making up $83.1 \%$ of the incidents [Table 3]. Other lodgment sites were the stomach, pyriform fossa, pylorus, and the duodenum. The majority of esophageal FBs were found in the upper esophagus (59.1\%) followed by mid esophagus $(26.8 \%)$. Each one of the 57 patients was symptomatic and dysphagia was reported by all. One patient had features of gastric outlet obstruction and another had upper gastrointestinal bleed. One patient had achalasia. In another patient, stricture due to malignancy was present in the lower end of the esophagus. None of the patients had eosinophilic esophagitis. Majority of the patients were treated in the emergency department and all the patients had dysphagia as the indication. The FBs such as meat piece, orange piece, coconut piece, mango, and nail were taken out within 1 week of ingestion. Dysphagia was the indication in the meat piece, coconut piece, and mango. Patients had features of gastric outlet obstruction in

\begin{tabular}{lccc}
\hline \multicolumn{3}{l}{ Table 1: Age distribution of patients $(\boldsymbol{n}=59)$} \\
\hline Age group (years) & \multicolumn{3}{c}{$\boldsymbol{n}(\%)$} \\
\cline { 2 - 4 } & Male & Female & Total \\
\hline $0-20$ & $10(16.9)$ & $10(16.9)$ & $20(33.9)$ \\
$21-40$ & $8(13.6)$ & $6(10.2)$ & $14(23.7)$ \\
$41-60$ & $10(16.9)$ & $6(10.2)$ & $16(27.1)$ \\
$61-80$ & $4(6.8)$ & $2(3.4)$ & $6(10.2)$ \\
$>81$ & $3(5.1)$ & - & $3(5.1)$ \\
Total & $35(59.4)$ & $24(40.6)$ & $59(100)$ \\
\hline
\end{tabular}

$n=$ Number of patients

\begin{tabular}{lc}
\hline Table 2: Frequency of different types of foreign bodies ingested \\
\hline Name of foreign body & $\boldsymbol{n}(\%)$ \\
\hline Coins & $17(28.8)$ \\
Chicken bone & $17(28.8)$ \\
Dentures & $12(20.3)$ \\
Meat piece & $4(6.8)$ \\
Orange piece & $2(3.4)$ \\
Fish bone & $1(1.7)$ \\
Coconut piece & $1(1.7)$ \\
Mango & $1(1.7)$ \\
Hairpin & $1(1.7)$ \\
Nail & $1(1.7)$ \\
Needle & $1(1.7)$ \\
Safety pin & $1(1.7)$ \\
Total & $59(100)$ \\
\hline
\end{tabular}

Table 3: Frequency of different sites of foreign body lodgment

\begin{tabular}{lc}
\hline Site & $n(\%)$ \\
\hline Esophagus & $49(83.1)$ \\
Upper & 30 \\
Middle & $12(20.3)$ \\
Lower & 7 \\
Stomach & $7(11.9)$ \\
Pyriform fossa & $1(1.7)$ \\
Pylorus & $1(1.7)$ \\
Duodenum & $1(1.7)$ \\
Total & $59(100)$ \\
\hline
\end{tabular}




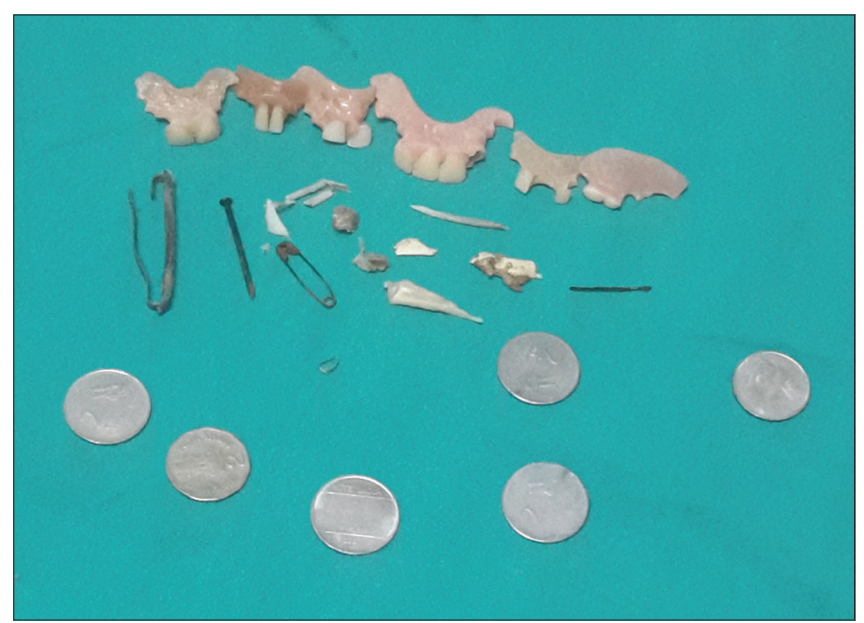

Figure 1: Various foreign bodies removed from the upper gastrointestinal tract by endoscopy

orange ingestion and upper gastrointestinal bleeding in nail ingestion. Detailed history from all the patients did not reveal any psychiatric illness among them. All the patients in whom coins were found as FBs had dysphagia. X-rays were not used in determining the location of FB in majority of the patients. Upper gastrointestinal endoscopy had 100\% overall success rate of retrieving the FBs in this study. No complication was encountered.

\section{Discussion}

FB ingestion and subsequent impaction are encountered commonly in clinical practice. Endoscopic removal has become the standard procedure for removal of FB lodgment in upper GIT. ${ }^{[10]}$ The majority of FB ingestions occur in the pediatric population. Children constituted one-third of our patients. True FB ingestion mainly with coins occurred in pediatric population as reported in other studies also. ${ }^{[1,9,11-14]}$ Incidents of coin ingestion were restricted to children only. One child had ingested a maximum of three coins and all were retrieved from stomach. The curiosity of children in dealing with coins is well known, and this explains why coins are the predominant FBs in pediatric age group. Dentures and food objects were the common type of FBs in adults and elderly. All our patients were symptomatic with dysphagia. Patients with esophageal FBs are almost always symptomatic with features of dysphagia, odynophagia, retrosternal pain, sore throat, FB sensation, retching, and vomiting. Other symptoms include choking, stridor, dyspnea, and hypersalivation. ${ }^{[15]}$ The most common anatomical site of FBs was the upper esophagus which is the narrowest area in esophagus. Similar observations have been made in other studies. ${ }^{[2,9,11,13,16]}$ Our experience in this study was a $100 \%$ success rate which is higher in comparison to other studies. ${ }^{[2,9]}$ We did not encounter any failure while retrieving the FBs. No complication was encountered during or after endoscopic removal. It is attributed to the kind of FBs which we encountered and were easily manipulated by endoscopic maneuvers. Flexible endoscopy is the best diagnostic and
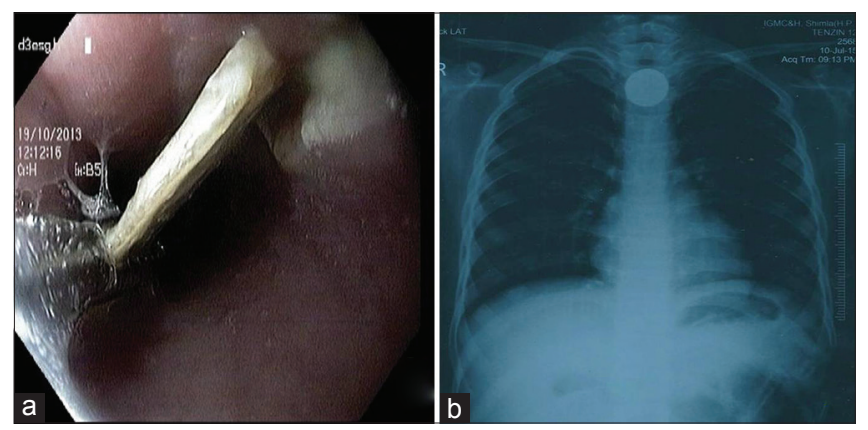

Figure 2: (a) Endoscopic view of a coin lodged in the upper esophagus. (b) Chest X-ray showing a coin in the upper esophagus

therapeutic approach in the management of FBs and food bolus impaction in the upper GIT, with success rates $>95 \%$ and complication rates of $0 \%-5 \% .{ }^{[15]}$ The complications mostly minor in the form of bleeding or mucosal erosion, tears, perforation, and abscess have been reported in some studies. ${ }^{[9,11,16]}$ The mean duration of time to endoscope patients in this study was $36.4 \pm 25.5 \mathrm{~h}$ which is longer as compared to $335.5 \pm 526 \mathrm{~min}$ found in another study. ${ }^{[2]}$ Twenty-two patients presented within $24 \mathrm{~h}$ and were managed. The FBs such as meat piece, orange piece, coconut piece, mango, and nail were taken out within 1 week of ingestion. Esophageal foreign objects and food bolus impacted in the esophagus should be removed within $24 \mathrm{~h}$ because delay decreases the likelihood of successful removal and increases the risk of complications. ${ }^{[15,17]}$ The risk for major complications (i.e., perforation with or without mediastinitis, retropharyngeal abscess, and aortoesophageal fistula) increases 14.1 times with FBs impacted for more than $24 \mathrm{~h}$ in the esophagus. ${ }^{[15]}$ The delay in endoscopic interventions in our study was due to the fact that patients attended pediatrics, otorhinolaryngology, cardiothoracic surgery, and general surgery departments initially. Associated esophageal pathology was observed in only two patients, i.e., one each with achalasia and malignant stricture. Underlying esophageal pathology is found in more than $75 \%$ of the patients presenting with food bolus impaction. The most frequently associated abnormalities were esophageal (mainly peptic) strictures (more than 50\%) and eosinophilic esophagitis (about 40\%). Less frequently, esophageal cancer or esophageal motility disorders, such as achalasia, diffuse esophageal spasm, and nutcracker esophagus, are the causes of food bolus impaction. ${ }^{[15]} \mathrm{X}$-ray is not sufficient and not required in patients with nonbony food bolus impaction and without clinical signs of perforation. Most true FBs can be identified radiographically; however, thin metal objects, wood, plastic, glass, and fish or chicken bones are not readily seen. Imaging is also recommended in complications such as aspiration, perforation-free mediastinal/peritoneal air, or subcutaneous emphysema. ${ }^{[15,17]}$ Although our study lacks novelty and many studies on endoscopic management of FBs are well reported in literature, to the best of our knowledge, this is the first study from the hill state of Himachal Pradesh, India. The state has limited resources in terms of availability of well-equipped endoscopy centers. This tertiary care center caters to the majority of the population of the state and being 
capable of dealing with such emergencies. Only 59 patients with FB ingestion reported to the hospital and have been included in the 5-year study. The number of patients reflects the picture of epidemiology regarding the hospital-based prevalence of FB ingestion in this region. Further, in this study, we experienced a $100 \%$ success rate in the retrieval of FBs without having a single complication.

\section{Conclusion}

It is recommended that all those patients with a history of FB ingestion and reporting initially to the departments of pediatrics, otorhinolaryngology, cardiothoracic surgery, and general surgery should be evaluated for possible endoscopic management.

\section{Financial support and sponsorship Nil.}

\section{Conflicts of interest}

There are no conflicts of interest.

\section{References}

1. Sugawa C, Ono H, Taleb M, Lucas CE. Endoscopic management of foreign bodies in the upper gastrointestinal tract: A review. World J Gastrointest Endosc 2014;6:475-81.

2. Yao CC, Wu IT, Lu LS, Lin SC, Liang CM, Kuo YH, et al. Endoscopic management of foreign bodies in the upper gastrointestinal tract of adults. Biomed Res Int 2015;2015:658602.

3. Abdullah BJ, Teong LK, Mahadevan J, Jalaludin A. Dental prosthesis ingested and impacted in the esophagus and orolaryngopharynx. J Otolaryngol 1998;27:190-4.

4. Webb WA. Management of foreign bodies of the upper gastrointestinal tract: Update. Gastrointest Endosc 1995;41:39-51.

5. Ginsberg GG. Management of ingested foreign objects and food bolus impactions. Gastrointest Endosc 1995;41:33-8.

6. Schwartz GF, Polsky HS. Ingested foreign bodies of the gastrointestinal tract. Am Surg 1976;42:236-8.

7. Mosca S, Manes G, Martino R, Amitrano L, Bottino V, Bove A, et al. Endoscopic management of foreign bodies in the upper gastrointestinal tract: Report on a series of 414 adult patients. Endoscopy 2001;33:692-6.

8. Smith MT, Wong RK. Foreign bodies. Gastrointest Endosc Clin N Am 2007;17:361-82, vii.

9. Emara MH, Darwiesh EM, Refaey MM, Galal SM. Endoscopic removal of foreign bodies from the upper gastrointestinal tract: 5-year experience. Clin Exp Gastroenterol 2014;7:249-53.

10. ASGE Standards of Practice Committee, Ikenberry SO, Jue TL, Anderson MA, Appalaneni V, Banerjee S, et al. Management of ingested foreign bodies and food impactions. Gastrointest Endosc 2011;73:1085-91.

11. Rybojad B, Niedzielska G, Niedzielski A, Rudnicka-Drozak E, Rybojad P. Esophageal foreign bodies in pediatric patients: A thirteen-year retrospective study. ScientificWorldJournal 2012;2012:102642.

12. Kochhar R, Aggarwal R, Goenka MK, Mehta S, Mehta SK. Management of foreign bodies in the upper gastrointestinal tract. Indian J Gastroenterol 1990;9:283-4.

13. Nijhawan S, Shimpi L, Mathur A, Mathur V, Roop Rai R. Management of ingested foreign bodies in upper gastrointestinal tract: Report on 170 patients. Indian J Gastroenterol 2003;22:46-8.

14. Shivakumar AM, Naik AS, Prashanth KB, Hongal GF, Chaturvedy G. Foreign bodies in upper digestive tract. Indian J Otolaryngol Head Neck Surg 2006;58:63-8.

15. Birk M, Bauerfeind P, Deprez PH, Häfner M, Hartmann D, Hassan C, et al. Removal of foreign bodies in the upper gastrointestinal tract in adults: European Society of Gastrointestinal Endoscopy (ESGE) clinical guideline. Endoscopy 2016;48:489-96.

16. Hong KH, Kim YJ, Kim JH, Chun SW, Kim HM, Cho JH. Risk factors for complications associated with upper gastrointestinal foreign bodies. World J Gastroenterol 2015;21:8125-31.

17. Singh B, Nijhawan S, Narayan KS, Kumar A. Endoscopic management of ingested foreign bodies and food impaction in esophagus. J Dig Endosc 2015;6:96-100. 